\title{
Sense of coherence and work-related patterns of behavior and experience among faculty nurse educators in Egypt
}

\author{
Amira Y. Sharaf*1, Eman E. Taha ${ }^{2}$ \\ ${ }^{1}$ Psychiatric Nursing and Mental Health Department, Faculty of Nursing, Alexandria University, Alexandria, Egypt \\ ${ }^{2}$ Nursing Education Department, Faculty of Nursing, Alexandria University, Alexandria, Egypt
}

Received: December 13, 2018

Accepted: December 20, 2018

Online Published: January 14, 2019

DOI: $10.5430 /$ jnep.v9n3p129

URL: https://doi.org/10.5430/jnep.v9n3p129

\begin{abstract}
Background: Nursing education is associated with high intensity work and potential burnout. Sense of coherence mitigates the effect of job stress and enhances work wellness. This study aims to identify work-related patterns of behavior and experience among nurse educators and examine the independent relationship between sense of coherence and workplace behavior patterns. Methods: The study used a cross-sectional descriptive design and a sample of 130 nurse educators teaching in the Faculty of Nursing, Alexandria University, Egypt. The nurse educators completed questionnaires measuring sense of coherence and work-related patterns of behavior and experience.

Results: Discriminant analysis delineated four work behavior patterns: healthy (16.2\%), frugal (1.5\%), overburdened (68.5\%), and burnout $(13.8 \%)$. Sense of coherence was positively associated with the healthy work pattern $(r=.66, p<.001)$, and negatively associated with the burnout $(r=-.63, p<.001)$ and overburdened $(r=-.18, p<.05)$ patterns. Regression analyses, controlling for years of teaching experience, indicated that a weak sense of coherence was associated with classification of nurse educators into the overburdened work pattern $\left(\mathrm{B}=-.05, \mathrm{SE}=.12\right.$, Wald $\left.\chi^{2}=13.13, p<.001\right)$ and the burnout work pattern $(\mathrm{B}=$ $-.10, \mathrm{SE}=.02$, Wald $\left.\chi^{2}=21.52, p<.001\right)$ compared to healthy work pattern.

Conclusions: The study findings highlight the importance of sense of coherence as a health-promoting resource in the workplace. Strategies are discussed for creating meaningful work experiences to reinforce a sense of coherence and simultaneously cultivate work-related wellness among nurse educators.
\end{abstract}

Key Words: Nurse educators, Sense of coherence, Work behavior

\section{INTRODUCTION}

Nursing education is characterized by multiple and necessary interactions between students, nurse educators/administrators, clients, families and health care providers, creating unique psychosocial demands for the profession. ${ }^{[1,2]}$ Strong evidence documents that nurse ed- ucators are confronted with immense pressures related to long work hours and heavy workloads; challenges to provide up-to-date, cost-effective learning experiences; conducting and publishing research; and participating in community activities. ${ }^{[3,4]}$ The role of nurse educator is multifaceted and stressful. Despite relatively little research on the quality

\footnotetext{
*Correspondence: Amira Y. Sharaf; Email: amira_psych@yahoo.com; Address: Psychiatric Nursing and Mental Health Department, Faculty of Nursing, Alexandria University, Alexandria, Egypt.
} 
of work life for nurse educators, the literature consistently reveals the negative impact of work-related stress on their physical and psychosocial well-being. ${ }^{[5,6]}$

Researchers have examined behaviors that help and hinder individual functioning in the workplace. ${ }^{[7-9]}$ Schaarschmidt and Fischer (2003), for example, developed an assessment method to identify four psychosocial work behavior patterns. ${ }^{[10]}$ Healthy Pattern represents a positive and functional attitude toward work. Individuals in this work pattern are ambitious and committed to their work, but also able to maintain emotional distance from work without giving up in the face of problems. They have feelings of inner peace and balance with a sense of emotional well-being, satisfaction with life and social support. Frugal Pattern, as its name implies, is characterized by prudent engagement in workrelated demands to save energy coupled with an unambitious attitude toward work. Individuals have a capacity to distance work-related problems, with a sense of satisfaction that arises primarily from other areas of life. Both patterns represent a generally healthy attitude toward work. Overburdened Pattern is characterized by excessive commitment to work with perfectionism. Individuals have difficulties distancing themselves from work-related problems and have a greater likelihood of resigning. Low satisfaction with life, lack of social support, and the absence of inner peace are portrayed in work-related overexertion and exhaustion. Burnout Pattern is reflected in low professional commitment and an increased tendency to resign in the face of difficult situations, corresponding with low mental resilience and inner balance, and dissatisfaction with work and life. Overburdened and burnout patterns, considered unhealthy, are likely to have detrimental effects on the individual's physical and mental health. ${ }^{[5]}$

Shimazu and Schaufeli (2009) found that "workaholism" (characteristic of overburdened pattern) versus "work engagement" (common to healthy pattern) was associated with somatic complaints, psychosocial distress, and a lack of life satisfaction. ${ }^{[11]}$ While this model of work behavior has been widely studied, to date, no research has been conducted to study the typology of working behaviors among nurse educators. ${ }^{[9,12,13]}$ Nonetheless, it is well documented that workload and burnout are the most persistent work disputes for nurse educators. ${ }^{[3,8,14,15]}$ A distinct need is to identify and investigate protective factors capable of buffering the effects of workplace stress for nurse educators.

An increasing number of researchers have investigated the types of resources and/or coping mechanisms that promote adaptation at work. ${ }^{[16,17]}$ Sense of coherence is an important internal psychological resource that facilitates stress management, and contributes to a sense of well-being. ${ }^{[18-21]}$ According to Antonovsky (1979, cited by Oosthuizen and Vanlill) sense of coherence, as a dispositional orientation toward life, is captured by three dimensions: comprehensibility, manageability, and meaningfulness. ${ }^{[17]}$ Comprehensibility is the extent to which internal and external stimuli are perceived as coherent. Manageability refers to perceptions that available resources are or will be adequate to meet the perceived demands. Meaningfulness, an emotional, motivational aspect of sense of coherence, refers to the belief that perceived demands are challenges rather than threats, and worth engaging. Harri (1998) suggested that a sense of coherence is a useful indicator of optimal workplace functioning for nurse educators. Harri found that among Finnish nurse educators sense of coherence was positively associated with positive perceptions of working life. ${ }^{[22]}$

The psychological well-being of nurse educators is a central factor in employee and organization success. Thus, it is imperative to understand patterns of work behavior among nurse educators, as well as the potential protective role of sense of coherence to minimize the more risky overburdened and burnout work patterns in academic settings. The present study will help identify effective strategies to promote nurse educator well-being. Ultimately, these will have a favorable impact on the quality of nurse educators' work and student learning as well as their prospective contributions to nursing and to society in general. The current study sought to identify work-related patterns of behavior among nurse educators and to examine the independent relationship between sense of coherence and patterns of workplace behavior. We hypothesized that sense of coherence would be independently and positively associated with the healthy pattern of work, and negatively associated with the overburdened and burnout patterns of work behavior.

\section{Methods}

\subsection{Design and setting}

A descriptive, cross-sectional design was used with data gathered from nurse educators at Faculty of Nursing, Alexandria University, Egypt.

\subsection{Sampling and participants}

The study included all nurse educators $(\mathrm{N}=130)$ who were currently active in a teaching position and willing to participate in the study.

\subsection{Measures}

\subsubsection{Sense of coherence}

Sense of coherence was measured with the Sense of Coherence (SOC) Scale developed by Antonovsky (1987). ${ }^{[23]}$ The 
scale consists of 29-item, each rated on a 7-point scale ranging from (1) very seldom/never to (7) very often, where the value seven represents the highest sense of coherence and the value one the weakest. The scale measures three dimensions: Comprehensibility (11items), manageability (10 items), and meaningfulness ( 8 items). The total score is obtained by summing all items; the total score ranges from 29 to 203 , with higher scores indicating a strong sense of coherence. The scale has established validity and reliability and used in previous studies. ${ }^{[9,15,24]}$ In the current study, Cronbach alpha values for the total scale and each components were $.91, .80$, .82 , and .76 , respectively.

\subsubsection{Work-Related Behavior and Experience Pattern (AVEM)}

AVEM (Arbeitsbezogenes Verhalten und-Erfahrungsmuster) questionnaire, was developed in German by Schaarschmidt and Fischer (2003) ${ }^{[10]}$ and adapted in other languages, has demonstrated validity and reliability. ${ }^{[5,9,12]}$ The English version is used to assess attitudes, experiences, behaviors traits and coping behavior in work situations. ${ }^{[25]}$ The questionnaire has 66 items that capture three major domains subdivided into 11 dimensions. Professional Commitment consists of five dimensions: subjective importance of work, professional ambitions, tendency to over exert, striving for perfection, and emotional distance. Resistance toward Stress is comprised of three dimensions: tendencies toward resignation, offensive coping with problems, and balance and mental stability. Emotional Well-being is comprised of three dimensions: satisfaction with work, life, and experiences of social support. Items are rated using a 5-point Likert scale ranging from strongly disagree to strongly agree, with high scores indicating better work experience. Cronbach's alpha in this study was .84. Four patterns of work-related behavior were delineated based on discriminant analysis.

\subsubsection{Demographic, academic variables}

A brief structured questionnaire was developed to gather information about nurse educator age, gender, professional title, academic degree, years of teaching experience, and work hours/week.

\subsection{Procedures}

\subsubsection{Ethical considerations}

The Ethical and Human Subjects Protection Committee of the Faculty of Nursing, Alexandria University reviewed and approved all study procedures. Written permission to carry out the study was obtained from the faculty dean. Written informed consent was obtained from research participants. Participant privacy and confidentiality were assured; all responses were anonymous; data were identified by code numbers and not linked to any personally identifiable information.
All data were grouped for analysis and reporting.

\subsubsection{Data collection}

A pilot study was conducted with a sample of ten nurse educators using the English version of AVEM and SOC measures. Results indicated that all measures were clear and understandable. Hence, the pilot study sample was included in the main study.

Over two months, study researchers met with the nurse educators in their academic departments, introduced the study and its purpose, and invited individual educators to participate in the study. The researchers informed the prospective respondents that their participation would be entirely voluntary, and their decision to participate or not to participate would not affect their work status. Self-administered questionnaires were distributed to those who agreed to participate and who signed the informed consent $(\mathrm{N}=145 / 150$ nurse educators). Of these, 130 (90\%) nurse educators participated and returned the questionnaires.

\subsubsection{Statistical analysis}

Descriptive statistics such as percentage, means, SD, min, max, kurtosis, and skew were calculated to describe study sample and test normality of data distribution. SPSS syntax of AVEM was received with the permission from the author. ${ }^{[10]}$ We used discriminant analyses to determine work behavior patterns for the nurse educators. The concurrence of the individual scores with the four reference typologies was estimated using a weighted linear combination of the scores of 11 dimensions. Based on individual concurrence profiles, nurse educators were assigned to one behavior pattern. For example, if the concurrence probability scores were healthy pattern $=0.75$, frugal pattern $=0.15$, overburdened pattern $=0.06$, and burnout pattern $=0.04$, the participant would be classified into healthy pattern. ${ }^{[26]}$ The higher the concurrence probability score, the stronger the tendency to act in a way characteristic of that designated behavior pattern.

We used Pearson correlation coefficients to examine the association between sense of coherence and work-related patterns of behavior. Chi-square $\left(\chi^{2}\right)$ test was used to examine for an association between classification patterns of work behavior and gender. One-way analysis of variance (ANOVA) with planned comparisons based on least significant difference (LSD) tests were used to examine for differences between classification pattern of work behavior and potential confounding variables including age, years of teaching experience, and work hours/week. Work pattern classification was not associated with gender and work hour/week, but was with age and years of teaching experience. The two latter variables were highly associated $(r=.99, p<.001)$, thus we used only years of teaching experience in the multinomial 
logistic regression models.

To examine for the independent relationship between sense of coherence and behavior patterns of nurse educators, controlling for confounding variables, we used multinomial logistic regression analysis. Pattern of work behavior was the criterion variable. For the main analyses, two multinomial logistic regression models were conducted. The first model used the healthy pattern of behavior as the reference category compared to the overburdened and burnout patterns. The second model used the overburdened pattern of behavior as the reference category compared to the healthy and burnout patterns. Reported $\mathrm{p}$ values were two tailed with significance set at $p<.05$.

\section{Results}

3.1 Sample demographic and academic characteristics The vast majority of the nurse educators $(92.3 \%)$ were female. Respondents' ages ranged from 23 to 74 years with a mean of 38.8 years $(\mathrm{SD}=14.4)$. One third of the sample $(33.1 \%)$ held bachelor degree of nursing science and had worked as demonstrators (clinical instructors). About $19 \%$ were assistant lecturer with a master degree. Lecturers with a doctorate degree of nursing science constituted $24.5 \%$ of the sample. Assistant professors, professors, and emeritus professors comprised $5.4 \%, 2.3 \%$, and $16.2 \%$ of the sample, respectively. Nine percent of the total sample $(n=12)$ occupied administrative positions (dean, vice deans, and department chairpersons). Professional experience in teaching ranged from 1 to 55 years with a mean of 15.3 years $(\mathrm{SD}=$ 13.6). The average number of hours worked per week was 29.5 hours $(\mathrm{SD}=6.5)$.

\subsection{Work-related patterns of behavior and experience}

Figure 1 shows that more than two-thirds $(68.5 \%)$ of the nurse educators engaged in the health risky overburdened pattern of work, whereas only $13.8 \%$ reported engaging in the maladaptive burnout pattern. Engagement in the healthy pattern was observed in $16.2 \%$ of the nurse educators. A particularly small percentage $(1.5 \%)$ of respondents had adopted the frugal pattern of behavior.

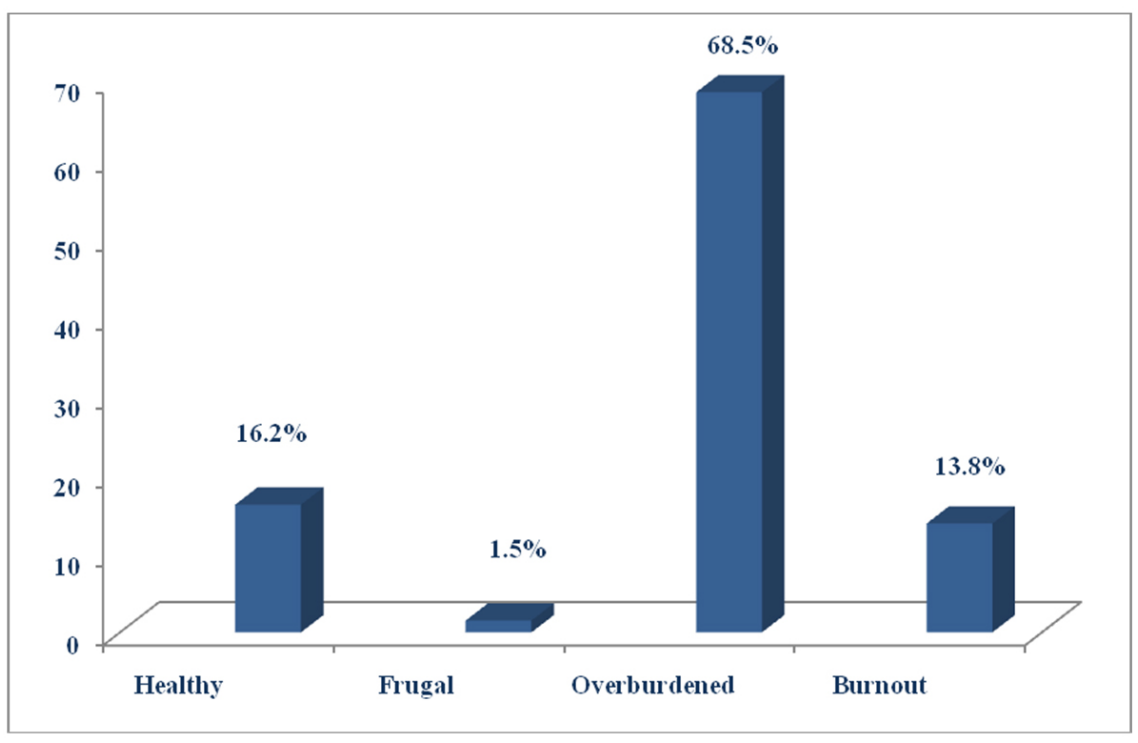

Figure 1. Percent distribution of work-related patterns of behavior and experience among faculty nurse educators

\subsection{Demographic and academic variables and work- related patterns of behavior and experience}

Examining for the effects of potential confounding variables among the demographic and academic variables, only years of teaching experience was associated with work-related patterns of behavior. That is, nurse educators classified in the healthy work pattern had significantly more years of teaching experience $(\mathrm{M}=24.1$ years) than nurse educators in the overburdened $(\mathrm{M}=14.4$ years $)$ or burnout $(\mathrm{M}=8.4$ years $)$ work patterns, $\mathrm{F}(2,125)=7.79, p<.01$.

\subsection{Sense of coherence and work-related patterns of be- havior and experience}

The total SOC score ranged from 77 to 188 , with a mean of 132.2 ( $\mathrm{SD}=24.8)$. Table 1 shows a statistically significant, positive correlation between the healthy work pattern and sense of coherence $(r=.66, p<.001)$. This relationship held for each of the three sense of coherence dimensions $(r$ $=.60, p<.001$ for each). On the other hand, the burnout work pattern was linked with a lower sense of coherence ( $r=$ - .63, $p<.001)$, and all three dimensions: comprehensibility 
$(r=-.56, p<.001)$, manageability $(r=-.63, p<.001)$, and meaningfulness $(r=-.57, p<.001)$. A weak but significant negative correlation was found between the overburdened pattern and sense of coherence $(r=-.18, p<.05)$; in contrast to the other work patterns, the overburdened pattern was weakly associated with only the meaningfulness dimension $(r=-.22, p<.05)$.

Table 1. Correlation between sense of coherence and its components and work-related patterns of behavior and experience among faculty nurse educators

\begin{tabular}{lllllll}
\hline$\dagger$ Pattern of behavior & Mean & SD & SOC & Comprehensibility & Manageability & Meaningfulness \\
\hline Healthy Pattern & .19 & .31 & $.66^{* *}$ & $.60^{* *}$ & $.60^{* *}$ & $.60^{* *}$ \\
Overburdened Pattern & .63 & .34 & $-.18^{*}$ & -.15 & -.13 & $-.22^{*}$ \\
Burnout Pattern & .15 & .25 & $-.63^{* *}$ & $-.56^{* *}$ & $-.63^{* *}$ & $-.57^{* *}$ \\
\hline
\end{tabular}

$\lceil$ The Frugal pattern was excluded from analysis due to low representation in the sample.* $p<.05 ; * * p<.001$.

3.5 Independent relationship between sense of coherence and work-related patterns of behavior and experience

Using multinomial logistic regression (see Table 2), with the healthy work pattern as the comparison (referent) group, sense of coherence was found to be negatively associated with classification of nurse educators into the overburdened work pattern $\left(\mathrm{B}=-.05, \mathrm{SE}=.12\right.$, Wald $\left.\chi^{2}=13.13, p<.001\right)$ and the burnout work pattern $\left(\mathrm{B}=-.10, \mathrm{SE}=.02\right.$, Wald $\chi^{2}$ $=21.52, p<.001)$. Comparison of the two unstandardized coefficients for the burnout ( $\mathrm{B}=-.10)$ versus the overburdened $(B=-.05)$ work patterns shows that sense of coherence had a stronger negative association with classification to the burnout versus overburdened pattern when compared to the healthy pattern. That is, those with the lowest sense of coherence were most likely to be classified in the burnout work pattern. In this analysis, we adjusted for the length of teaching experience, which had no influence on likelihood that a nurse educator was classified into the overburdened or the burnout work patterns.

A separate but similar analysis was conducted using the overburdened work pattern as the comparison (referent) category. This allowed us to compare the association between sense of coherence and classification for the burnout versus the overburdened pattern, while adjusting for teaching experience. Compared to the overburdened pattern, we found that nurse educators with a stronger sense of coherence were less likely to be classified in the burnout pattern $(\mathrm{B}=-.05, \mathrm{SE}=.02$, Wald $\left.\chi^{2}=8.46, p<.01\right)$. Taken together, the results indicate that nurse educators with a strong sense of coherence were more likely to have a healthy pattern of work behavior, and nurse educators with a weak sense of coherence were more likely to be engaged in work behaviors consistent with burnout, and that this association was not influenced by years of teaching experience.

Table 2. Multinomial regression results for the relationship between sense of coherence and work-related patterns of behavior and experience among faculty nurse educators

\begin{tabular}{|c|c|c|c|}
\hline †Work-related Behavior Pattern & B & SE & Wald $\chi^{2}$ \\
\hline \multicolumn{4}{|l|}{ Overburdened Work Pattern } \\
\hline Sense of Coherence & -.05 & .12 & $13.13^{*}$ \\
\hline Years of Teaching Experience & -.01 & .02 & .08 \\
\hline \multicolumn{4}{|l|}{ Burnout Work Pattern } \\
\hline Sense of Coherence & -.10 & .02 & $21.52 *$ \\
\hline Years of Teaching Experience & -.05 & .04 & 1.26 \\
\hline
\end{tabular}

${ }^{\top}$ The reference category is: Healthy Work Pattern. ${ }^{*} p<.001$.

\section{Discussion}

This study examined the relationship between sense of coherence and work-related patterns of behavior among Egyptian nurse educators. The study revealed that a high proportion of nurse educators displayed work patterns commensurate with risk for over exhaustion. Nursing faculty experience challenges associated with teaching classes, supervising laboratory experiences and clinical work, participating in research activities, supervising master and doctorate theses, and engaging in administrative tasks that have strict and often concomitant deadlines, exacerbating workloads and time pressure. In addition, given the importance of educational ac- 
creditation, nurse educators face tremendous demands keeping up to date in the knowledge and skills required for professional practice in a competitive job market. Oermann (1998) reported that workload creates imbalance between nurse educators' personal and professional lives, rendering them susceptible to frustration as they strive to meet demands of their multifaceted professional roles. ${ }^{[4]}$ Kieschke and Schaarschmidt (2008) found risky work patterns of overburdened and burnout common among teachers. ${ }^{[26]}$ Harri (1996) reported that nurse educators in Finland perceived workload as the worst feature of their working life, followed by inadequacy of personal resources, administrative issues, poor interpersonal relationships, and inconvenient physical workplace environments. ${ }^{[3]}$ Feeling burdened at work may contribute to exhaustion and cynicism that erode one's sense of competency at work; a factor increases the likelihood of transition to the maladaptive burnout work pattern. ${ }^{\text {[27-30] }}$ In support of this, Cam (2001), in a study of predictors of burnout among university nurse educators in Turkey, found that job demands was the strongest predictor of all components of burnout: emotional exhaustion, depersonalization, and decreased personal accomplishment. ${ }^{[31]}$ Taken together, the overburdened and burnout work patterns require proactive actions to maintain sense of well-being at workplace.

The study results demonstrated that sense of coherence was independently associated with the healthy work pattern among nurse educators. This result is consistent with other studies that have highlighted the impotence of sense of coherence as a source of resilience, and that can buffer the effect of stress in workplace. ${ }^{[15,24,32]}$ A study of Finnish nurse educators found that sense of coherence correlated positively with healthy functioning and job satisfaction, and negatively with perceived job burden and stress symptoms. ${ }^{[22]}$ Individuals with a strong sense of coherence are capable of adapting to stressors in a way that promotes professional commitment as well as their sense of well-being at the workplace. In addition, conceiving of stressors as an opportunity for growth and with a sense of understandability can enhance self-confidence and self-fulfillment, which in turn serves to motivate successful work performance. Congruent with these interpretations, Harri (1998) reported that persons with a strong sense of coherence are able to develop realistic assessments of their own efficacy, and balance work and lifestyle, both of which promote healthy work behaviors. ${ }^{[22]}$ The current results also suggested that individuals with a strong sense of coherence are able to direct their energy to control and solve work problems in lieu of disengagement or resignation. Such problem-focused approaches are reported as effective in reducing stress and its related disorders, and enhancing psychological health at work. ${ }^{[33,34]}$
The finding that a low sense of coherence was associated with a tendency toward the maladaptive burnout work pattern was reasonable. Antonovsky (1987, cited by Rothmann et al.) documented persons with a low sense of coherence tend to perceive life events as chaotic and unstable. They are apt to experience life events as uncontrollable, and interpret their adaptive efforts as making little sense and perhaps as futile. ${ }^{[15]}$ Thus, a low sense of coherence may predispose an individual toward passivity, helplessness and disengagement, which in turn can lead to burnout. This interpretation is supported in part by findings from Sarmiento et al. (2004) who found that nurse educators who were able to mobilize resources to accomplish work experienced less emotional exhaustion, an important contributor to burnout. ${ }^{[8]}$ Along the same line, Van der Colff and Rothmann (2009) in a study of 818 registered nurses in South Africa found that registered nurses with a weak sense of coherence tended to adopt emotion-focused strategies in dealing with stress, which in turn exacerbated emotional exhaustion and feelings of depersonalization. $^{[35]}$

While the bivariate finding demonstrated that senior nurse educators compared to junior educators were more likely to engage in a healthy work pattern, years of teaching experience was no longer associated with work patterns when sense of coherence was incorporated into the analyses. This may reflect that a sense of coherence, as a fundamental internal resource, influences and positively shapes the quality of one's teaching experience, and thus become self-reinforcing. Clearly, experienced nursing educators with a strong sense of coherence are able to organize their work, spend a reasonable effort to accomplish tasks without experiencing exhaustion, and to perform effectively. They may be more likely to use self-reflection and seek timely support, reducing feelings of being burdened by work and its concomitant emotional strain. On the other hand, more junior faculty nursing often need time and experience to build external work resources in terms of establishing peer and administrative support, shaping a reasonable and stable work environment, creating a balanced workload, and learning to effectively share decision making. New faculty also need learn to shape their task performance in a way that reinforces their sense of competency. Positive work experiences can develop compatibility between internal and external resources to meet the work demands which in turn can mitigate feelings of work burden and/or emotional exhaustion. Consistent with this interpretation, Kamel and Abou-Hashish (2015) found that nursing educators in the professor rank were more competent in handling workplace uncertainty than were educators holding lower academic ranks. ${ }^{[36]}$ Similarly, Lackritz (2004) reported that less experienced faculty had the additional strain of estab- 
lishing their academic career, and learning to balance work and personal life demands, whereas more experienced faculty were more adept in managing job demands and creating work-life balance. ${ }^{[28]}$

\section{CONCLUSION AND RECOMMENDATIONS}

\subsection{Conclusion}

The process of nursing education is a ubiquitous burden source for nurse educators. Sense of coherence, the focus of the current study, can be an important internal resource for professional functioning. It has the health-promoting effects of enhancing one's sense of well-being and work engagement.

\subsection{Study strengths and limitations}

This first study delineated types of work behaviors among nurse educators and examined the protective role of personal coherence in enhancing work wellness. The strengths of the current study arise from its high participation rate (90\%), which increases the likelihood of population representation. In addition, assessments were based on valid and reliable measures, increasing the reproducibility of the findings. A number of study limitations need to be considered, as well as directions for further research. First, the cross-sectional design does not allow inference of causality, thus it is possible that healthy work behaviors promote a sense of coherence. Longitudinal studies are needed to examine the stability of sense of coherence in predicating the changes on nurse educator patterns of work behavior across time. Second, the study relies only on self-report measures to assess work behavior, which may create biased or socially desirable responses. Thus, future studies should consider incorporating objective measures such as observational methods. Third, the study did not investigate contextual factors of working organization such as collegial and administrative support, professional autonomy and control, or participation in decision- making processes, which are likely to shape work-related patterns of behavior, and perhaps one's sense of coherence.

\subsection{Implications for nursing education and practice}

The study shed light on the importance of enhancing sense of coherence in the work life of nursing faculty to cultivate work engagement as well as sense of well-being in the workplace. Intervention approaches could be considered at both the organizational and individual levels. For instance, at the organizational level, a sense of coherence can be improved by promoting communication which is transparent, timely, and ordered. This approach is likely to help nurse educators perceive work life as structured and explicable, enhancing their sense of comprehensibility. ${ }^{[15]}$ Organizational methods to improve sense of control and manageability include reasonable and realistic workload assignments, participation in work assignment decision-making, taking into account the demands and complexity of educators' roles, and providing structure for consistent and constructive feedback. Taken together, sharing responsibility, facilitating autonomy, and providing resources to meet work demands create a more meaningful work environment. Along this line, Kamel and Abou-Hashish (2015) recommended that creating a humanistic work environment that endowed Egyptian nurse educators with a sense of support, sharing, and autonomy can improve educators' sense of job well-being and satisfaction with life. ${ }^{[36]}$ Similarly, Mayer and Boness (2011) reported that sense of coherence in work place can be strengthened by open communication, appreciation of achievement, and value relatedness, justice and humor. ${ }^{[37]}$ Also, recommended is creating a mentoring program within the organization to socialize and empower young faculty to meet the challenges of their new academic roles.

On the individual level, increasing educators' awareness of how to function optimally at workplace through honing mindfulness-based stress reduction skills is highly recommended. For instance, Super et al. (2015) highlighted that helping individuals to be focused in the present and not overwhelmed by emotions, heightens one's ability to perceive and understand the situations. This in turn, may empower individuals to identify resources to develop more realistic goals and priorities and interpret their efforts as worthy and meaningful in mastering difficult situations. ${ }^{[38]}$

\section{ACKNOWLEDGEMENTS}

A special thanks to all of the nurse educators who participated in this study for contributing to our understanding of work patterns among nurse educators.

\section{CONFlicts OF InTEREST Disclosure}

The authors declare that they have no competing interests.

\section{REFERENCES}

[1] DalPezzo NK, Jett KT. Nursing faculty: a vulnerable population. J Nurs Educ. 2010; 49(3): 132-6. PMid:19877574 https ://doi .or g/10.3928/01484834-20090915-04

[2] Harri M. Assessing the quality of the working life of nurse educators in Finland: perception of nurse educators and their spouses. J Adv
Nurs. 1995 Feb; 21(2): 378-86. PMid:7714298

[3] Harri M. 'I love my work...' but the 'best' and the 'worst' in nurse educators' working life in Finland. J Adv Nurs. 1996 June; 23(6): 1098 109. PMid:8796456 https ://doi.org/10.1046/j.1365-2648. 1996.01395. $\mathrm{x}$

[4] Oermann MH. Work-related stress of clinical nursing faculty. J Nurs 
Educ. 1998 Oct; 37(7): 302-4. PMid:9796868

[5] Schulz M, Damkroger A, Voltmer E, et al. Work-related behavior and experience pattern in nurse: impact on physical and mental health. J Psychiatr Ment Health Nurs. 2011 Jun; 18 (5): 411-7. https://doi.org/10.1111/j.1365-2850.2011.01691.x

[6] Nieuwenhuijsen K, Bruinvels D, Frings-Dresen M. Psychosocial work environment and stress-related disorders, a systematic review. Occup Med (Lond). 2010 Jun; 60(4): 277-86. PMid:20511268 http://doi.org/10.1093/occmed/kqq081

[7] Urakawa K, Yokoyama K, ltoh H. Sense of coherence is associated with reduced psychological responses to job stressors among Japanese factory workers. BMC Research Notes. 2012 July; 5: 247.

[8] Sarmiento TP, Laschinger HK, Iwasiw C. Nurse educators' workplace empowerment, burnout, and job satisfaction: testing Kanter's theory. J Adv Nurs. 2004 Apr; 46(2): 134-43. PMid:15056326 http://dx.doi.org/10.1111/j.1365-2648.2003.02973.x

[9] Basinska MA, Andruszkiewicz A, Grabowska M. Nurses' sense of coherence and their work related patterns of behavior. Int J Occup Med Environ Health. 2011 Sep; 24(3): 256-66. PMid:21833694 http://dx.doi.org/10.2478/S13382-011-0031-1

[10] Schaarschmidt U, Fischer AW. Work-Related Behavior and Experience Pattern. 2nd ed. Frankfurt: Swets \& Zeitlinger; 2003.

[11] Shimazu A, Schaufeli WB. Workaholism good or bad for employee wellbeing? The distinctiveness of workaholism and work engagement among Japanese employees. Ind Health. 2009 Oct; 47(5): 495-502. PMid:19834258 https://doi.org/10.2486/indhealth.47.4 95

[12] Voltmer E, Wingenfeld K, Spahn C, et al. Work-related behavior and experience patterns of nurses in different professional stages and settings compared to physicians in Germany. IJMHN. 2013 April; 22(2): 180-89. https://doi.org/10.1111/j.1447-034 9.2012.00855.x

[13] Voltmer E, Schwappach DL, Frank E, et al. Work-related behavior and experience patterns and predictors of mental health in German physicians in medical practice. Fam Med. 2010 June; 42(6): 433-9.

[14] Gerolamo AM, Roemer GF. Workload and nurse faculty shortage: implications for policy and research. Nurs Outlook. 2011 Sep-Oct; 59 (5): 259-65. PMid:21497860 https://doi.org/10.1016/j. outlook.2011.01.002

[15] Rothmann S, Steyan IJ, Mostert K. Job stress, sense of coherence and work wellness in an electricity supply organization. S.Afr.J.Bus.Manage. 2005 Jan; 36 (1): 55-63.

[16] Jimenez P, Bregenzer A, Kallus K, et al. Enhancing resources at the workplace with health promoting leadership. Int J Environ Res Public Health. 2017 Oct; 14(10): 1264

[17] Oosthuizen JD, Vanlill B. Coping with stress in the workplace. SAJIP. 2008; 34(1): 64-9. https://doi.org/10.4102/sajip.v34i1. 421

[18] Eriksson M, Lindstrom B. Antonvsky's sense of coherence scale and the relation with health: a systematic review. J Epidemiol Community Health. 2006 May; 60(5): 376-81. PMid:16614325 https://doi.org/10.1136/jech.2005.041616

[19] Mayer CH, Krause C. Promoting mental health and salutogenesis in transcultural organizational and work contexts. International Review of Psychiatry. 2011 Dec; 23(6): 495-500. PMid:22272586 https://doi.org/10.3109/09540261.2011.636549

[20] Vogt K, Jenny GJ, Bauer GF. Comprehensibility, manageability and meaningfulness at work: construct validity of a scale measuring work-related sense of coherence. SAJIP. 2013 Sep; 39(1): 1-8.

[21] Mc Gee SL, Holtge J, Maercker A, et al. Sense of coherence and stress-related resilience: investigating the mediating and moderat- ing mechanisms in the development of resilience following stress or adversity. Front. Psychiatry. 2018 Aug; 9: 378.

[22] Harri M. The sense of coherence among nurse educators in Finland. Nurse Educ Today. 1998 April; 18(3): 202-12. https://doi.org/ $10.1016 / \mathrm{S} 0260-6917$ (98) 80080-4

[23] Antonovsky A. Unraveling the mystery of health. How people manage stress and stay well. San Francisco: Jossey-Bass Publishers; 1987.

[24] Derbis R, Jasinski AM. Work satisfaction, psychological resiliency and sense of coherence as correlates of work engagement. Cogent Psychology. 2018 Mar; 5(1): 1-16.

[25] Schaarschmidt U, Fischer AW. Work-Related Behavior and Experience Pattern. University of Potsdam, Germany, 2003.

[26] Kieschke U, Schaarschmidt U. Professional commitment and Health among teachers in Germany: a typological approach. Learning and Instruction. 2008; 18(5): 429-37. https://doi.org/10.1016/j . learninstruc. 2008.06.005

[27] Shirey MR. Stress and Burnout in nursing faculty. Nurse Educ. 2006 May-Jun; 31(3): 95-7. PMid:16708030 https://doi .org/10.1 097/00006223-200605000-00002

[28] Lackritz JR. Exploring burnout among university faculty: incidence, performance, and demographic issues. Teaching and Teacher Education. 2004 Oct; 20(7): 713-29. https://doi.org/10.1016/j.ta te.2004.07.002

[29] Portoghese I, Galletta M, Coppola RC, et al. Burnout and workload among health care workers: the moderating role of job control. Saf Health Work. 2014 Sep; 5(3): 152-7.

[30] Aboushousha AA, Taha EE. Relationship between academic nurse educators' burnout and organization work climate. Proceedings of the 6th International Scientific Nursing Conference; 2014 April 21-44; Faculty of Nursing, Helwan University, Egypt.

[31] Cam O. The burnout in nursing academicians in Turkey. Int J Nurs Stud. 2001 Apr; 38(2): 201-7. https://doi.org/10.1016/S002 0-7489(00)00051-1

[32] Gui L, Barriball KL, While AE. Job satisfaction of nurse teachers: a literature review. Part II: effects and related factors. Nurse Educ Today. 2009; 29(5): 477-87. PMid:19118928 https://doi.org/ $10.1016 / j$.nedt .2008 .11 .003

[33] Posadzki P, Glass N. Self-efficacy and the sense of coherence: narrative review and conceptual synthesis. Scientific World Journal. 2009 Sep 14; 9: 924-33. PMid:19768348 https://doi .org/10.1100/ tsw.2009.107

[34] Lee HF, Kuo CC, Chien TW, et al. A metanalysis of the effects of coping strategies on reducing nurse burnout. Appl Nurs Res. 2016 Aug; 31: 100-10.

[35] Van der Clof JJ, Rothmann S. Occupational stress, sense of coherence, coping, burnout and work engegment of register nurses in South African. SA Journal of Industrial Psychology. 2009; 35(1): 1-10.

[36] Kamel NF, Abou-Hashish E. The relationship between psychological need satisfaction, job affective wellbeing and work uncertainty among the academic nurse educators. Journal of Nursing Education and Practice. 2015; 5(8): 99-108. https://doi.org/10.5430/jn ep.v5n8p99

[37] Mayer C, Boness C. Interventions to promoting sense of coherence and transcultural competence in educational context. Int Rev Psychiatry. 2011 Dec; 23(6): 516-24. https://doi .org/10.3109/0954 0261.2011 .637906

[38] Super S, Wagemakers MAE, Picavet HSJ, et al. Strengthening sense of coherence: opportunities for theory building in health promotion. Health Promot Int. 2015 Dec; 31(4): 869-78. https: //doi.org/10.1093/heapro/dav071 